\title{
Heterogeneity of aortic smooth muscle cells: A determinant for regional characteristics of thoracic aortic aneurysms?
}

\author{
Hisashi Sawada ${ }^{1}$, Jeff Z. Chen ${ }^{1,2}$, Bradley C. Wright ${ }^{1}$, \\ Mary B. Sheppard ${ }^{1,2,3,4}$, Hong S. Lu ${ }^{1,2}$, Alan Daugherty ${ }^{1,2}$ \\ 'Saha Cardiovascular Research Center, University of Kentucky, Lexington, Kentucky, USA; \\ 2Department of Physiology, University of Kentucky, Lexington, Kentucky, USA; \\ ${ }^{3}$ Department of Family and Community Medicine, University of Kentucky, Lexington, Kentucky, USA; \\ ${ }^{4}$ Department of Surgery, University of Kentucky, Lexington, Kentucky, USA
}

\section{INTRODUCTION}

Thoracic aortic aneurysm (TAA) is defined as a permanent dilation of the thoracic aorta that is associated with a propensity for rupture and dissection. The general term of TAA covers the manifestation of aortic dilation that occurs in a wide range of syndromic and non-syndromic conditions. Within these conditions, aortic pathologies manifest in distinct regions of the thoracic aorta.

Smooth muscle cells (SMCs) are the only cell type resident in the normal aortic media and are crucial in maintaining aortic wall integrity. The functional properties of SMCs, such as contractility and proliferation, are different in each aortic region and may contribute to the pathophysiology of TAA. SMCs in the thoracic aorta are heterogeneous in their embryologic origin. ${ }^{[1]}$ It has been inferred that the different embryonic origins may have functional difference, although this has not been defined in the context of TAA development. This editorial summarizes recent publications that implicate embryonic origins of SMCs that are responsible for the regional characteristics of TAAs.

\section{REGION-SPECIFIC FEATURES OF TAAS}

The thoracic aorta is composed of four distinct regions: aortic root, ascending aorta, aortic arch, and descending portion. ${ }^{[2]}$ Of note, $60 \%$ of TAAs impact the aortic root and/or the ascending aorta in human. ${ }^{[3]}$ For example, TAAs in Marfan syndrome and Ehlers-Danlos syndrome occur most often in the aortic root. ${ }^{[4-6]}$ TAAs in LoeysDietz syndrome and Turner syndrome preferentially form in both the aortic root and the ascending aorta..$^{[7-10]}$ Aortic aneurysms in patients with bicuspid aortic valve are most commonly reported in the ascending aorta. ${ }^{[1]]}$ This regional specificity extends to inflammatory TAA as well; syphilis and Takayasu arteritis mainly affect the ascending aorta. ${ }^{[12,13]}$ Thus, the wide range of aortic root and ascending aortic aneurysm pathologies suggests that these two regions are more susceptible to aortic pathologies.

This distinct regional distribution is also observed in multiple TAA mouse models. Fibrillin 1 haploinsufficient (fibrillin $1^{\mathrm{C} 1041 \mathrm{G} /+}$ ) mice and hypomorphic (fibrillin $\left.1^{\mathrm{mgR} / \mathrm{mgR}}\right)$ mice are commonly used Marfan syndrome mouse models. Both models exhibit aortic root and ascending aortic dilation. ${ }^{[14-19]}$ Mice with postnatal deletion of TGF- $\beta$ receptor 1 or 2 in SMCs that mimic Loeys-Dietz syndrome develop aneurysms spanning from the aortic root to the descending aorta. ${ }^{[7,20-23]}$ In a non-syndromic TAA mouse model, chronic infusion with angiotensin II (AngII) leads to the formation of TAAs that are restricted to the ascending aortic region. ${ }^{[24,25]}$ Mechanisms driving this regional specificity of TAAs in human and mouse have not been defined. 


\section{SMC FUNCTIONS IN TAAS}

SMC functions, including contractility and proliferation, play a pivotal role in aortic homeostasis and vary in different aortic regions. However, the potential impact of these functions on the regional specificity of TAAs has not been defined. AngII promotes aortic contraction but only in the infrarenal region of the mouse aorta. ${ }^{[2]}$ In addition, chronic infusion of AngII induces medial hyperplasia of the ascending aorta but hypertrophy in the other aortic regions. ${ }^{[27]}$ Furthermore, SMCs in the ascending aorta are more susceptible to TGF- $\beta 1$-induced cell proliferation compared to SMCs in the abdominal aorta. ${ }^{[28]}$ These functional differences may be associated with the pathophysiology of TAAs.

In human TAA tissues, the expression of a marker of SMCs, $\alpha$-smooth muscle actin, is decreased. ${ }^{[21,22]}$ Interestingly, this expression shows a gradient that decreases from the luminal to the adventitial aspects of the media. Simultaneously, proteoglycan deposition, a marker of extracellular matrix remodeling, occurs predominantly in the adventitial aspect of the media. In addition, aortic dissection, a disease characterized by the creation of a false channel within the aortic media, preferentially occurs in the outer third of the aortic media. ${ }^{[2]}$ Aneurysmal tissue from TAA mouse models also exhibits a gradient of medial pathologies that is consistent with human TAA features. For example, Marfan syndrome mouse models (fibrillin $1^{\mathrm{C} 1041 \mathrm{G} /+}$ and fibrillin $1^{\mathrm{mgR} / \mathrm{mgR}}$ ), Loeys-Dietz syndrome mouse models (TGF- $\beta$ receptor 1 or 2 deletion in SMCs), and the AngII-induced TAA mouse models exhibit prominent medial pathologies such as medial thickening and elastin fragmentation that preferentially forms in the outer medial aspect (Figure 1). ${ }^{[19-25,30]}$ Thus, medial pathologies show a gradient toward the outer medial aspect in human and mouse TAAs.

\section{EMBRYONIC ORIGINS OF SMCS IN THE THORACIC AORTA}

Using mice with lineage tracing constructs, recent publications have delineated the heterogeneous embryologic origins of SMCs within the thoracic aorta. SMCs in the thoracic aorta are derived from three different embryonic origins: the cardiac neural crest (CNC), the second heart field (SHF), and the somites (Figure 2A). ${ }^{[1,31-33]}$ The CNC originates from the ectoderm, and $\mathrm{CNC}$-derived SMCs are expressed from the aortic root to the end of the aortic arch. ${ }^{[32-34]}$ The SHF is derived from the pharyngeal arches of the mesoderm, and SHF-derived cells are expressed from the aortic root to the branch of the innominate artery. ${ }^{[33,35,36]}$ The CNC and SHF interact with each other

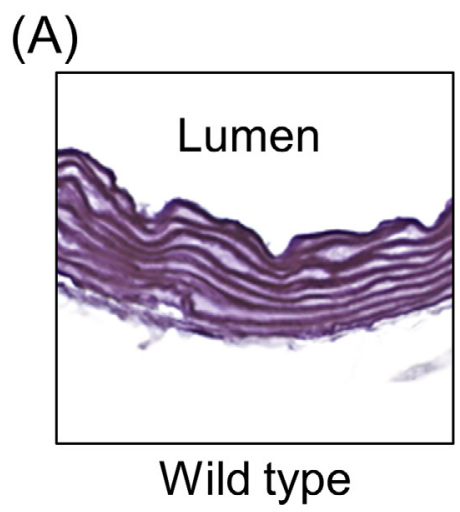

(B)

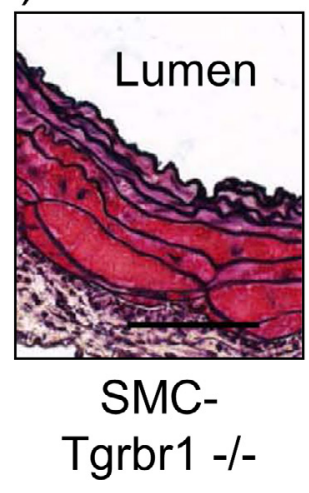

(C)

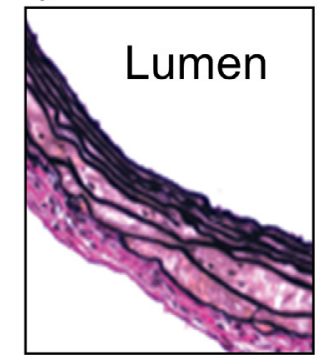

SMC-

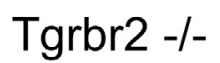

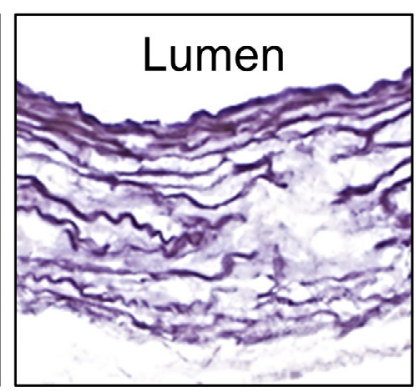

Fbn1C1041G/+
(D)

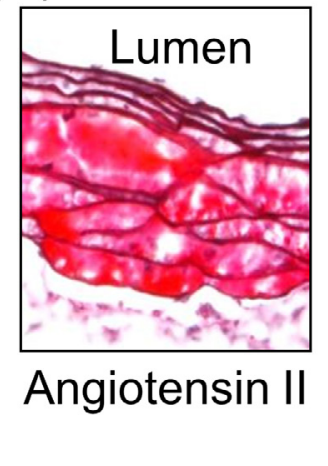

Figure 1: Representative ascending aortic images of (A) wild type and fibrillin1 ${ }^{\text {c10416/+ }}$ mice, $^{[19]}$ (B) SMC-specific TGF- $\beta$ receptor 1 deleted mice, ${ }^{[23]}$ (C) SMC-specific TGF- $\beta$ receptor 2 deleted mice, ${ }^{[22]}$ and (D) angiotensin II-infused mice. ${ }^{[25]}$ 


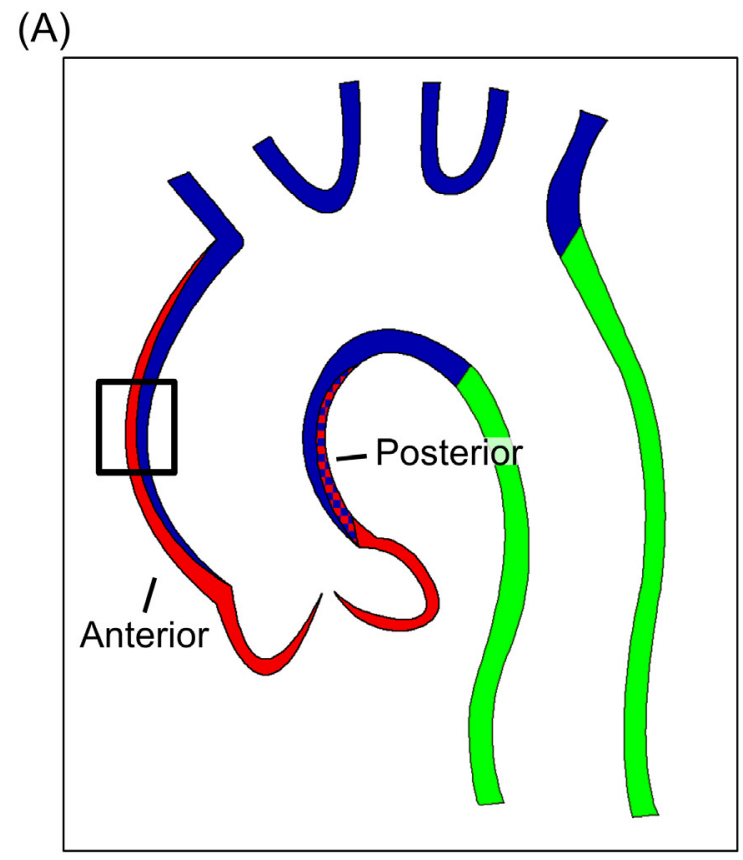

(B)

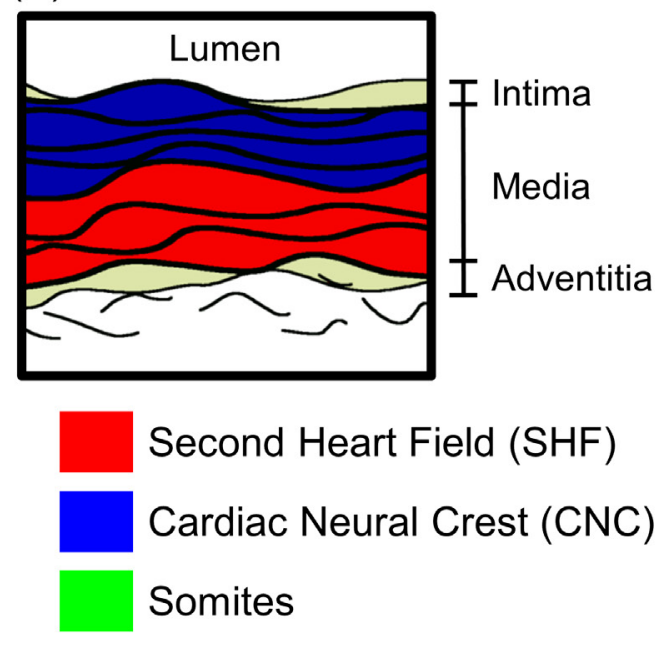

Figure 2: (A) Schematic illustration of embryonic origins of SMCs in the thoracic aorta. (B) Magnified image is captured from the black box. Blue, red, and green in the images indicate CNC-, SHF-, and somite-derived cells, respectively.

and are essential for the development of the ascending aorta. ${ }^{[37]}$ The descending aorta is derived from the somites, which are formed from the paraxial mesoderm. ${ }^{[38-40]}$

Although SMCs of the aortic arch and descending aorta are derived from a single origin, the ascending aorta contains overlapping SMCs from both $\mathrm{CNC}$ and SHF origins. An SMC lineage tracing study has discovered that CNC- and SHF-derived SMCs in the ascending aorta show a spatially distinct distribution (Figure 2B). ${ }^{[33]}$ CNC-derived SMCs reside in the inner medial aspect of the anterior portion and in the transmedia of the posterior portion of the ascending aorta. Conversely, SHF-derived SMCs locate in the outer medial layers of both the anterior and posterior portions. Thus, the outer medial SMCs of the ascending aorta form a sleeve populated by SHF-derived SMCs, which is coincident with medial pathologies.

The regional specificity and medial gradient of aortic pathology in TAAs correspond to the distribution of embryologic origin of SMCs. In addition, the functional properties of SMCs are different in different aortic regions. Thus, SMCs of different embryonic origins may have different functions that affect the pathophysiology of TAAs. While the proximal thoracic aorta of chicken and mouse is populated with SMCs of these embryonic origins, it is unknown whether this specific pattern of $\mathrm{CNC}$ and SHF origins is present in humans. Further studies that define CNC and SHF origins in postnatal tissue to determine whether human tissue is populated with SMCs of these origins are needed.

\section{CONCLUSION}

TAA formation exhibits regional specificity, which is also characterized by pathologic changes in the outer medial layers of the aorta. The distinct embryonic origins of SMCs in the thoracic aorta may explain these specific pathologic features. This is one facet of the many unknown features in the mechanisms of TAAs.

\section{Sources of Funding}

The authors' research work was supported by the National Heart, Lung, and Blood Institute of the National Institutes of Health (HL133723 and HL139748) and the American Heart Association (18SFRN339600001). HS is supported by an AHA postdoctoral fellowship (18POST33990468). JZC and MBS are supported by the National Center for Advancing Translational Sciences (UL1TR001998). The content in this manuscript is solely the responsibility of the authors and does not necessarily represent the official views of the National Institutes of Health.

\section{Conflict of Interest}

None declared.

\section{REFERENCES}

1. Majesky MW. Developmental basis of vascular smooth muscle diversity. Arterioscler Thromb Vasc Biol 2007; 27: 1248-58.

2. Goldfinger JZ, Halperin JL, Marin ML, Stewart AS, Eagle KA, Fuster V. Thoracic aortic aneurysm and dissection. J Am Coll Cardiol 2014; 64: 1725-39. 
3. Isselbacher EM. Thoracic and abdominal aortic aneurysms. Circulation 2005; 111: 816-28.

4. Dietz HC, Cutting GR, Pyeritz RE, Maslen CL, Sakai LY, Corson GM, et al. Marfan syndrome caused by a recurrent de novo missense mutation in the fibrillin gene. Nature 1991; 352: 337-9.

5. Judge DP, Dietz HC. Marfan’s syndrome. Lancet 2005; 366: 1965-76.

6. Wenstrup RJ, Meyer RA, Lyle JS, Hoechstetter L, Rose PS, Levy HP, et al. Prevalence of aortic root dilation in the Ehlers-Danlos syndrome. Genet Med 2002; 4: 112-7.

7. Loeys BL, Chen J, Neptune ER, Judge DP, Podowski M, Holm T, et al. A syndrome of altered cardiovascular, craniofacial, neurocognitive and skeletal development caused by mutations in tgfbr1 or tgfbr2. Nat Genet 2005; 37: 275-81.

8. Lindsay ME, Dietz HC. Lessons on the pathogenesis of aneurysm from heritable conditions. Nature 2011; 473: 308-16.

9. Ostberg JE, Donald AE, Halcox JP, Storry C, McCarthy C, Conway GS. Vasculopathy in turner syndrome: Arterial dilatation and intimal thickening without endothelial dysfunction. J Clin Endocrinol Metab 2005; 90: 5161-6.

10. Cleemann L, Mortensen KH, Holm K, Smedegaard H, Skouby SO, Wieslander SB, et al. Aortic dimensions in girls and young women with turner syndrome: A magnetic resonance imaging study. Pediatr Cardiol 2010; 31: 497-504.

11. Verma S, Siu SC. Aortic dilatation in patients with bicuspid aortic valve. N Engl J Med 2014; 370: 1920-9.

12. Roberts WC, Barbin CM, Weissenborn MR, Ko JM, Henry AC. Syphilis as a cause of thoracic aortic aneurysm. Am J Cardiol 2015; 116: 1298-1303.

13. Matsumura K, Hirano T, Takeda K, Matsuda A, Nakagawa T, Yamaguchi $\mathrm{N}$, et al. Incidence of aneurysms in takayasu's arteritis. Angiology 1991; 42: 308-15.

[14. Judge DP, Biery NJ, Keene DR, Geubtner J, Myers L, Huso DL, et al. Evidence for a critical contribution of haploinsufficiency in the complex pathogenesis of marfan syndrome. J Clin Invest 2004; 114: 172-81.

15. Pereira L, Lee SY, Gayraud B, Andrikopoulos K, Shapiro SD, Bunton T, et al. Pathogenetic sequence for aneurysm revealed in mice underexpressing fibrillin-1. Proc Natl Acad Sci U S A 1999; 96: 3819-23.

16. Cook JR, Clayton NP, Carta L, Galatioto J, Chiu E, Smaldone S, et al. Dimorphic effects of transforming growth factor-beta signaling during aortic aneurysm progression in mice suggest a combinatorial therapy for marfan syndrome. Arterioscler Thromb Vasc Biol 2015; 35: 911-7.

17. Habashi JP, Doyle JJ, Holm TM, Aziz H, Schoenhoff F, Bedja D, et al. Angiotensin II type 2 receptor signaling attenuates aortic aneurysm in mice through erk antagonism. Science 2011; 332: 361-5.

18. Habashi JP, Judge DP, Holm TM, Cohn RD, Loeys BL, Cooper TK, et al. Losartan, an at 1 antagonist, prevents aortic aneurysm in a mouse model of marfan syndrome. Science 2006; 312: 117-21.

19. Wanga S, Hibender S, Ridwan Y, van Roomen C, Vos M, van der Made I, et al. Aortic microcalcification is associated with elastin fragmentation in marfan syndrome. J Pathol 2017; 243: 294-306.

20. Schmit BM, Yang P, Fu C, DeSart K, Berceli SA, Jiang Z. Hypertension overrides the protective effect of female hormones on the development of aortic aneurysm secondary to alk5 deficiency via ERK activation. Am J Physiol Heart Circ Physiol 2015; 308: H115-25.

21. Hu JH, Wei H, Jaffe M, Airhart N, Du L, Angelov SN, et al. Postnatal deletion of the type II transforming growth factor-beta receptor in smooth muscle cells causes severe aortopathy in mice. Arterioscler Thromb Vasc Biol 2015; 35: 2647-56.

22. Li W, Li Q, Jiao Y, Qin L, Ali R, Zhou J, et al. Tgfbr2 disruption in postnatal smooth muscle impairs aortic wall homeostasis. J Clin Invest 2014; 124: 755-67.
23. Yang P, Schmit BM, Fu C, DeSart K, Oh SP, Berceli SA, et al. Smooth muscle cell-specific tgfbr 1 deficiency promotes aortic aneurysm formation by stimulating multiple signaling events. Sci Rep 2016; 6: 35444.

24. Daugherty A, Rateri DL, Charo IF, Owens AP, Howatt DA, Cassis LA. Angiotensin II infusion promotes ascending aortic aneurysms: Attenuation by ccr2 deficiency in apoe-/- mice. Clin Sci (Lond) 2010; 118: 681-9.

25. Rateri DL, Davis FM, Balakrishnan A, Howatt DA, Moorleghen JJ, O'Connor WN, et al. Angiotensin II induces region-specific medial disruption during evolution of ascending aortic aneurysms. Am J Pathol 2014; 184: 2586-95.

26. Rateri DL, Moorleghen JJ, Balakrishnan A, Owens AP, 3rd, Howatt DA, Subramanian V, et al. Endothelial cell-specific deficiency of Ang II type 1a receptors attenuates Ang II-induced ascending aortic aneurysms in LDL receptor-/- mice. Circ Res 2011; 108: 574-81.

27. Owens AP, 3rd, Subramanian V, Moorleghen JJ, Guo Z, McNamara CA, Cassis LA, et al. Angiotensin II induces a region-specific hyperplasia of the ascending aorta through regulation of inhibitor of differentiation 3. Circ Res 2010; 106: 611-9.

28. Topouzis S, Majesky MW. Smooth muscle lineage diversity in the chick embryo. Dev Biol 1996; 178: 430-45.

29. Osada H, Kyogoku M, Ishidou M, Morishima M, Nakajima H. Aortic dissection in the outer third of the media: What is the role of the vasa vasorum in the triggering process? Eur J Cardiothorac Surg 2013; 43: e82-8.

30. Trachet B, Piersigilli A, Fraga-Silva RA, Aslanidou L, Sordet-Dessimoz $\mathrm{J}$, Astolfo A, et al. Ascending aortic aneurysm in angiotensin II-infused mice: Formation, progression, and the role of focal dissections. Arterioscler Thromb Vasc Biol 2016; 36: 673-81.

31. Waldo KL, Hutson MR, Ward CC, Zdanowicz M, Stadt HA, Kumiski D, et al. Secondary heart field contributes myocardium and smooth muscle to the arterial pole of the developing heart. Dev Biol 2005; 281: 78-90.

32. Jiang X, Rowitch DH, Soriano P, McMahon AP, Sucov HM. Fate of the mammalian cardiac neural crest. Development 2000; 127: 1607-16.

33. Sawada H, Rateri DL, Moorleghen JJ, Majesky MW, Daugherty A. Smooth muscle cells derived from second heart field and cardiac neural crest reside in spatially distinct domains in the media of the ascending aorta-brief report. Arterioscler Thromb Vasc Biol 2017; 37: 1722-6.

34. Hutson MR, Kirby ML. Model systems for the study of heart development and disease. Cardiac neural crest and conotruncal malformations. Sem Cell Dev Biol 2007; 18: 101-10.

35. Buckingham M, Meilhac S, Zaffran S. Building the mammalian heart from two sources of myocardial cells. Nat Rev Genet 2005; 6: 826-35.

36. Srivastava D. Making or breaking the heart: From lineage determination to morphogenesis. Cell 2006; 126: 1037-48.

37. Waldo KL, Hutson MR, Stadt HA, Zdanowicz M, Zdanowicz J, Kirby ML. Cardiac neural crest is necessary for normal addition of the myocardium to the arterial pole from the secondary heart field. Dev Biol 2005; 281: 66-77.

38. Christ B, Huang R, Scaal M. Formation and differentiation of the avian sclerotome. Anat Embryol (Berl) 2004; 208: 333-50.

39. Pouget $C$, Gautier R, Teillet MA, Jaffredo T. Somite-derived cells replace ventral aortic hemangioblasts and provide aortic smooth muscle cells of the trunk. Development 2006; 133: 1013-22.

40. Wasteson P, Johansson BR, Jukkola T, Breuer S, Akyurek LM, Partanen $\mathrm{J}$, et al. Developmental origin of smooth muscle cells in the descending aorta in mice. Development 2008; 135: 1823-32.

How to cite this article: Sawada H, Chen JZ, Wright BC, Sheppard MB, Lu HS, Daugherty A. Heterogeneity of aortic smooth muscle cells: A determinant for regional characteristics of thoracic aortic aneurysms? J Transl Intern Med 2018; 6: 93-6. 